\title{
Understanding functional efficiency of a sewer overflow screening device using combined CFD and analytical modeling
}

\author{
$\underline{\text { M.A. Aziz }}$, M.A. Imteaz ${ }^{\mathrm{a}}$, N. Huda and J. Naser \\ ${ }^{a}$ Faculty of Engineering \& Industrial Sciences, Swinburne University of Technology, Melbourne, Australia \\ Email:aaziz@swin.edu.au
}

\begin{abstract}
Recent developments of urban drainage are more concerned with water quality issues and aesthetic concern in receiving water bodies as sewer overflow can cause detrimental effects on the environment. The impacts of such uncontrolled sewer overflow include environmental, aesthetic, ecological and public health concerns. To overcome these problems different types of screening devices are used. Due to increasing public complaints, scientists and engineers are focusing on retention of the entrained sewer solids within the sewer overflow device.
\end{abstract}

There are a number of different screening systems used in sewer overflow locations. Some of the common drawbacks in the available commercial devices include inadequate screening capacity, external power needs and high cost. Research has been undertaken to develop a new sewer overflow screening device to overcome these existing limitations. Design criteria for the conceptual device needs to have a self-cleansing capacity to work efficiency in unstaffed remote locations, robust start-stop operations, device fail outlet for extreme events, no moving parts, no sophisticated electrical-mechanical signal, low maintenance and establishment cost etc.

Establishing an experimental setup involves significant cost and time; moreover it is important to maximize functional efficiency of the device as alteration of the device would be an expensive, troublesome and at times difficult to customize accordingly to existing urban drainage systems. State of art CFD modelling techniques can provide detail on the impacts of velocity, water level, shear stress, wave reflection etc.

A self-cleansing sewer overflow screening device with a sewer overflow chamber, a rectangular tank and a slotted ogee weir to capture the gross pollutants was investigated. To design an efficient sewer overflow screening device a 3D fluid dynamics model (CFD) was used. To understand dynamic flow properties such as velocity, water levels, wave refection and shear stress, two different inlet orientations; parallel and perpendicular to the weir direction were tested. The results are compared using simplified analytical model based on well-established physical laws.

Numerical results show that the flow is not uniform (across the width of the inclined surface) at the top of the inclined surface; however flow becomes uniform near the bottom. Uniform flow at the bottom of the inclined surface will help to remove pollutants adhered to the perforations. Due to varying water levels (high water level near the right side and low water near the left side), near the top of the weir surface, the self-cleansing property will not be as effective near the top region.

The CFD simulated shear stress is less than the analytical model as it is unable to consider flow undulations. Analysis of the shear stress along the flow path was performed to identify efficient self-cleansing screeners. CFD simulation showed that the shear stress increases significantly at the bottom of the inclined surface of the sewer screener device, which suggests that, the location of screen should be towards the bottom. Discussion of the comparison of CFD and analytical results will help to design an effective and efficient sewer overflow screening device.

Keywords: $\quad$ Sewer Solids, Screening Device, CFD Modelling, Analytical model, screener location 


\section{INTRODUCTION}

Under wet weather conditions, sewer overflows cause serious environmental, aesthetics and public health concerns. Sewer solids disperse, float or wash into rivers and eventually settle, creating odours and toxic/corrosive conditions in bottom mud deposits. It degrades aesthetic quality either in general appearance such as increasing 'dirtiness appearance' and in the actual presence of specific, objectionable items such as floating debris, sanitary discards/faecal matter, scum or even parts of car tyres. To address these problems, research involves different types of screening devices for remove these pollutants. Screening of sewer solids is a controlled process that is desirable to the sewer system. It needs to be automated in order to ensure operational safety and effective use in unstaffed remote locations. Most environmental regulations prefer floatable controls and safety to device failed conditions. These requirements lead to the need to research different and better types of screening devices and screenings handling systems to select the most appropriate for a particular installation, especially at isolated locations.

There are a number of different screening systems used in sewer overflow locations. One of the most common used in practice is the rotary screen proposed by Moffa (1997), which consists of a large rotating drum that is slightly angled to maximize dewatering. The angle of the drum ensures effective dewatering as the screenings travel up to the drum where they are removed from the unit. Metcalf and Eddy (1991) proposed a centrifugal screen having a series of screens attached to a cage that rotates around a vertical axis and where the flow enters from the bottom and flows upward to a deflection plate at the top of the unit and is collected from outside the cage. Other types include disc types that consist of a flat disk covered with a screening media that rotates about a horizontal axis. The solids are retained by the screening media while the influent enters the submerged portion of the disc. A cleansing brush mechanism known as a brush raked fine screen is mounted on a drive shaft that slowly rotates in a 360 degree circle. In addition to these, Moffa (1997) used an inclined static screen that acted as a sieve to remove solids from the liquid stream. On a sewer overflow screening device, a weir screen acts as a barrier to retain floatable and other solids and is cleaned by a rotating brush that is powered by the energy of water flowing over a water wheel or by an electric motor. Faram et al. (2001) tested a hydro jet device installed in USA, Australia and mainland Europe. However in most cases the device was directly associated with blockages of the sewerage system.

Some of the common drawbacks in the available commercial devices include inadequate screening capacity, external power needs and high cost (Aziz et al., 2013). Simon and Phillips (2008) developed a sewer overflow screening device with temporary holding tanks that provides transient storage and real time control of sewer systems. The device has no moving parts, has a robust stop/start operation, works as self-cleaning device and has no sophisticated electrical mechanical circuit. An update of the device (Aziz et al., 2010) under investigation in the current research is a proposed noble self-cleansing sewer overflow screening device having a sewer overflow chamber, a rectangular tank and a slotted ogee weir to capture the gross pollutants. No external power source with mechanical or electrical components is needed for this self-cleansing device.

To design an efficient, effective and optimized sewer overflow screening device, 3D computational fluid dynamics model (CFD) was used. To understand dynamic flow properties such as velocity, water levels, wave refection and shear stress, two different inlet orientations, parallel and perpendicular to the weir direction were tested. The results are compared with a simplified analytical model based on well-established (analytical) physical laws.

\section{SCREENING MECHANISM}

This proposed overflow sewer device will be installed downstream of an existing sewer overflow location. Figure 1a shows the overflow sewerage screen device in the $1^{\text {st }}$ phase. As sewage builds up in the left chamber (A), water pressure will push the floatable ball upward in the right chamber (B), which is connected to the left chamber via a pipe (C). As the floatable ball goes upward, it will block the hole on the upper surface. It also shows the plan view of the proposed device, showing the left and right box chambers and the vertical dotted lines (right) representing the screening device. The thick horizontal dotted lines represent the pipe connected to the left and right chambers. The thick circle is the hole at the bottom of right chamber (B) and the dotted circle is the floatable ball. The sewage builds up in the left chamber (A) until it becomes full, at which time the sewage will overflow the weir type structure.

Figure $1 \mathrm{~b}$ shows the second phase of the scenario with the overflowing sewer. Towards the bottom of the sloping weir, the screen will exclude the solids while allowing the water to pass through the screen, bypassing the right chamber (B) and then to exit to the creek or waterway through two bypass channels (D).

The third phase of the scenario is when the flow has subsided and the sewage level in the left chamber (A) is receding. Once the sewage level drops down to a certain level, the buoyancy pressure on the ball will reduce and the ball will drop, allowing the trapped pollutants to exit into the right chamber (through the pipe ' $\mathrm{C}$ ') and then be flushed back into the sewer system (E). 


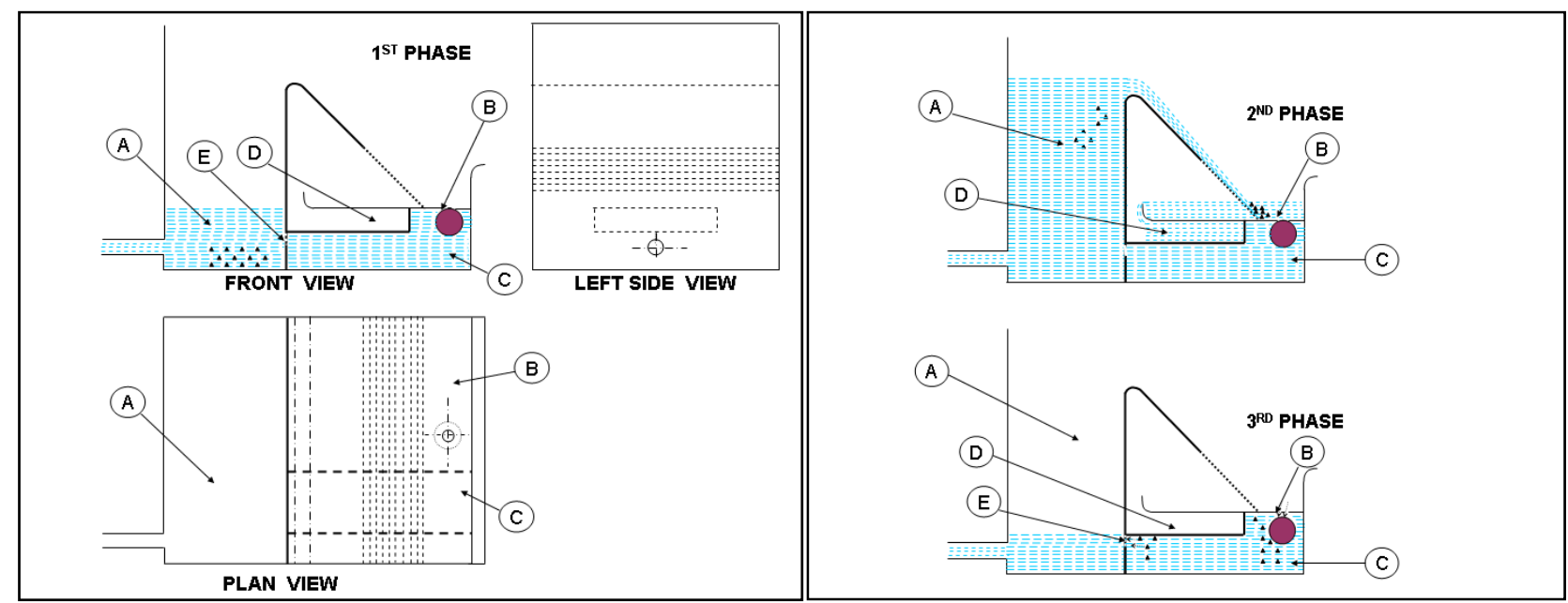

Figure 1a. Working diagram of the Sewer Overflow device, Figure 1b. Ogee weir is used to overflow the sewer water and pollutants are trapped in point B. Floating valve is open and pollutants are again return back to the system.

\section{COMPUTATIONAL FLUID DYNAMICS (CFD) MODELLING}

The hydrodynamic characteristics of the overflow sewer screening device were investigated using a computational fluid dynamic model by adopting finite volume method in Euler - Euler approach. The 3D multiphase flow numerical model was developed using commercially available CFD package AVL Fire 2009.2 (AVL, 2008) to predict the flow over the ogee weir. The CFD modelling for sewer overflow screening device involves multiphase simulation where gas and liquid phases interact with each other and there is significant exchange of momentum between phases. The model developed includes the following features,

- Unsteady state multiphase solution for momentum and continuity was considered.

- Standard $k-\varepsilon$ turbulence model for the turbulence modelling was employed.

- A cell centred finite volume approach was used to discretise the governing equations and the resulting discretised equations were solved iteratively using segregated approach.

- Pressure and velocity were coupled using the Semi Implicit Method for Pressure Linked Equations (SIMPLE) algorithm.

- Least square fit approach was used for the calculation of the derivatives

- For momentum and turbulence, first order upwind differencing scheme was used whereas central differencing scheme with second order accuracy was used for the continuity equation

- Screening device walls were treated by standard wall functions with no slip condition.
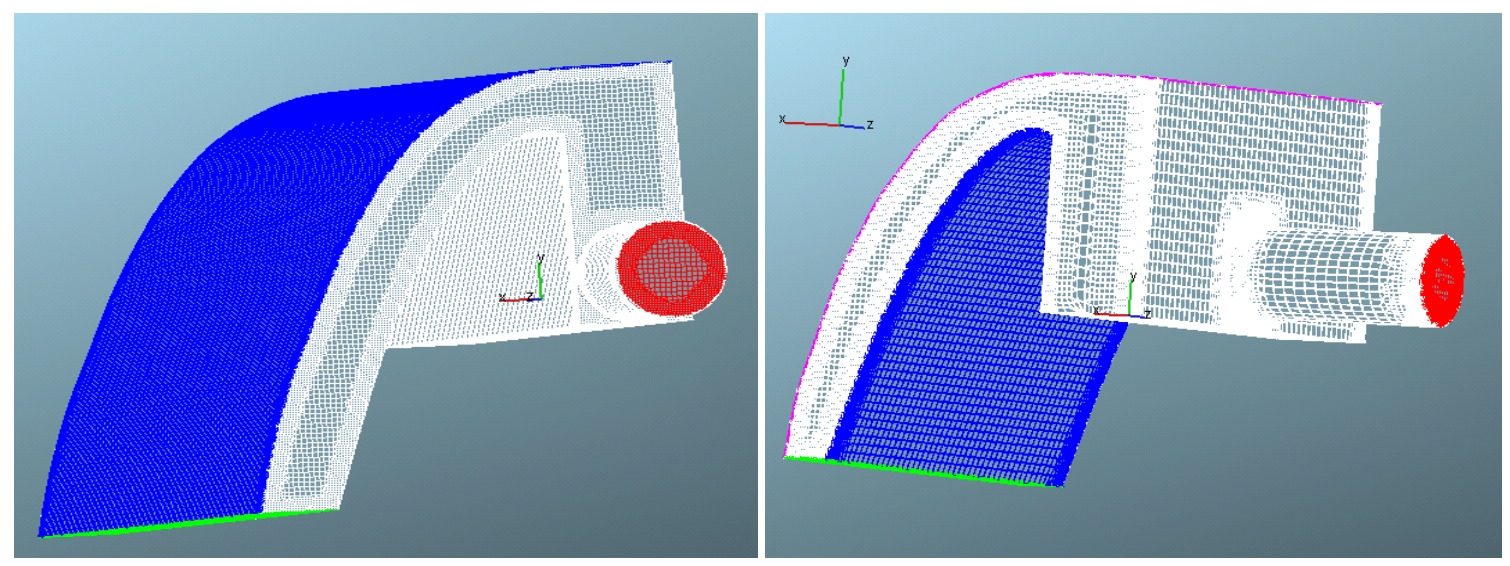

Figure 2. Position 1 (left) is the inlet parallel and Position 2 (right) is the inlet perpendicular to weir direction

The screening device has a rectangular tank $(1 \mathrm{~m} \mathrm{X} 0.2 \mathrm{~m})$, an ogee weir and an inclined surface. The height of ogee weir bottom is $0.75 \mathrm{~m}$ and the diameter of the inlet pipe is $0.2 \mathrm{~m}$. A design flow rate of $40 \mathrm{l} / \mathrm{s}$ was considered for this analysis. The outflow was assumed as free flow and perpendicular to outlet surface at the edge of weir. Two different inlet positions as shown in Figure 2 were chosen to analyse water level, flow velocity and shear stress distribution for the proposed screening device. The model was simulated for a period of 180 seconds with a computational time step of 0.05 second. The results of the final time step are shown in the Figure 3 . A colour scale 
contour was used to differentiate air and water with scale 1 (red) as water and scale 1e-006 (blue) as air. The total number of cells used for computations for Position 1 was 27659 cells whereas for Position 2, it was 38619 cells. The results of the final time steps volume fraction are shown in the Figure 3.

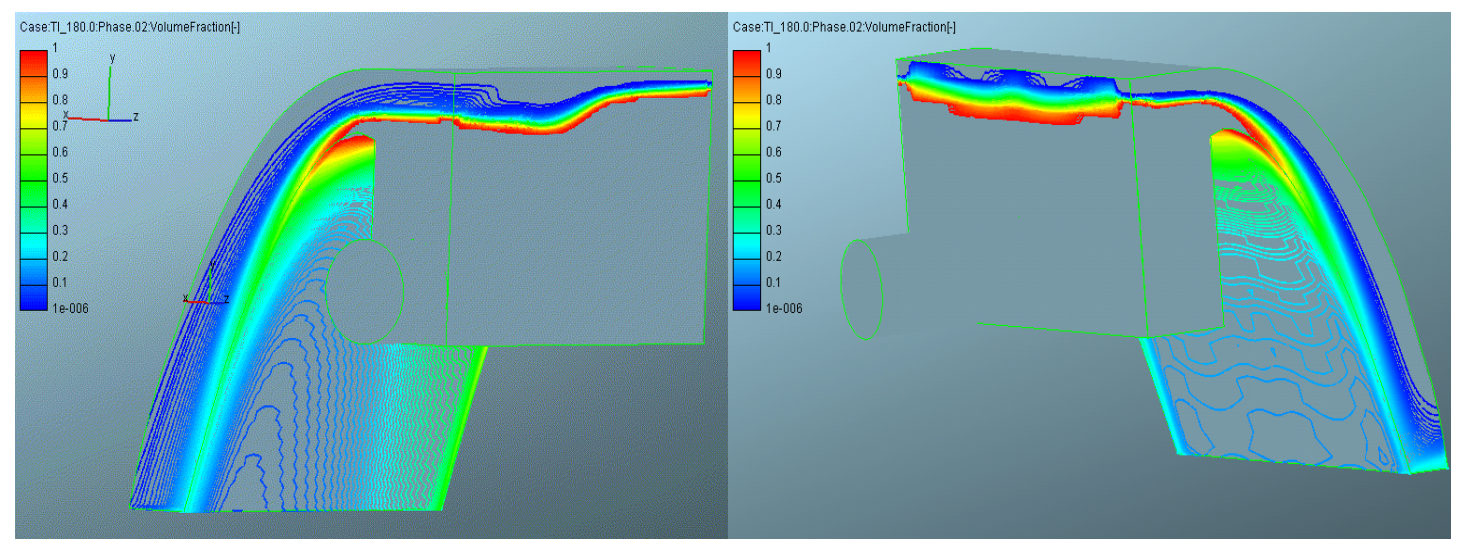

Figure 3. Volume fraction of water for condition 1 (left) and Position 2 (right)

In determining water level, assumptions were made based on the flooding and drying concept reported by Stelling (1984), which suggest a value $\geq 50 \%$ of the volume fraction is considered as water level. Flow reflection is dominating over the cross section profile of the sewer overflow device.

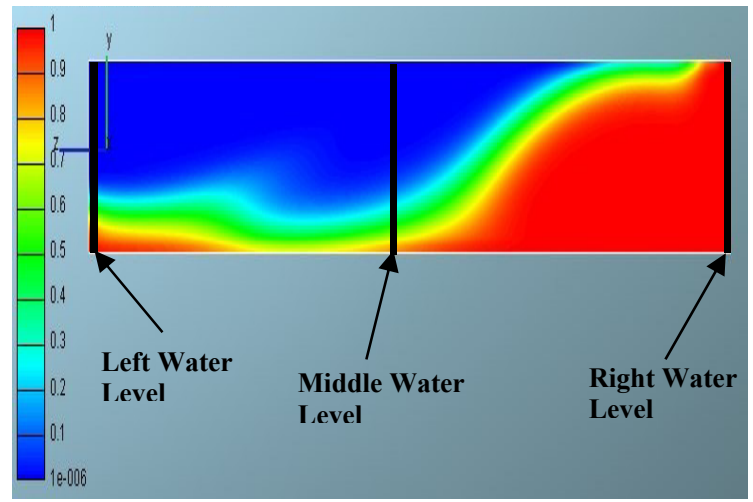

While analysing the 3D numerical results for water level and velocities, three distinct sections across the width of the weir were selected, left, middle and right, to show changing profiles. The position of left, middle and right in the simulation result are shown in Figure 4 . The first set over the weir, and the second and third sets, are $3 \mathrm{~cm}$ and $6 \mathrm{~cm}$ downstream of the ogee weir respectively. Parallel to the weir inlet are considered as points 1, 2, 3 whereas perpendicular to the weir inlet are numbered as points 4,5 , 6 for analysing numerical results.

Figure 4. Water levels over weir showing different position

\section{ANALYTICAL SOLUTIONS}

To find an analytical solution using the Navier-Stokes equations, some simple assumptions are considered. Firstly, the flow is considered to be steady and uniform, flowing under the influence of gravity and parallel to the bottom surface while the effect of air viscosity at the free surface is negligible. As the surface is inclined we have to consider the body force. Therefore with constant viscosity, the Navier Stokes Equation becomes

$$
\begin{aligned}
& \rho\left(\frac{\partial u}{\partial t}+u \frac{\partial u}{\partial x}+v \frac{\partial u}{\partial y}\right)=-\frac{\partial P}{\partial x}+\rho g_{x}+\mu\left(\frac{\partial^{2} u}{\partial x^{2}}+\frac{\partial^{2} u}{\partial y^{2}}\right) \\
& \rho\left(\frac{\partial v}{\partial t}+u \frac{\partial u}{\partial x}+v \frac{\partial v}{\partial y}\right)=-\frac{\partial P}{\partial y}+\rho g_{y}+\mu\left(\frac{\partial^{2} v}{\partial x^{2}}+\frac{\partial^{2} v}{\partial y^{2}}\right)
\end{aligned}
$$

The variables $u$, and $v$ represent the velocities in the $x$ - and $y$ - coordinates; $\rho=$ density; $\mu=$ dynamic viscosity of water; $\mathrm{P}=$ defined as pressure; $\mathrm{g}_{\mathrm{x}}, \mathrm{g}_{\mathrm{y}}$ are gravitational force in $\mathrm{x}$ and $\mathrm{y}$ directions. As we consider $1 \mathrm{D}$ flow situation, the Z-direction was ignored and as the flow is steady $\delta / \delta \mathrm{t}=0$. Moreover the flow is parallel to the inclined surface, i.e. $\mathrm{X}$-axis, so $\delta \mathrm{u}_{\mathrm{x}} \delta \mathrm{x}=0$ and $\mathrm{u}=0$. As the flow is uniform the flow takes over a constant depth ' $h$ ' which leads pressure gradient $\delta \mathrm{P} / \delta \mathrm{x}=0$. If ' $\mathrm{Z}$ ' is the vertical direction, the potential per unit mass due to body force is $\mathrm{g}_{\mathrm{z}}$. Therefore the components of body force in $\mathrm{X}$ and $\mathrm{Y}$ directions are:

$$
\begin{aligned}
& X=-\partial g_{z} / \partial x=-g \partial z / \partial x=g \sin \theta \\
& Y=-\partial g_{z} / \partial y=-g \partial z / \partial y=-g \cos \theta
\end{aligned}
$$




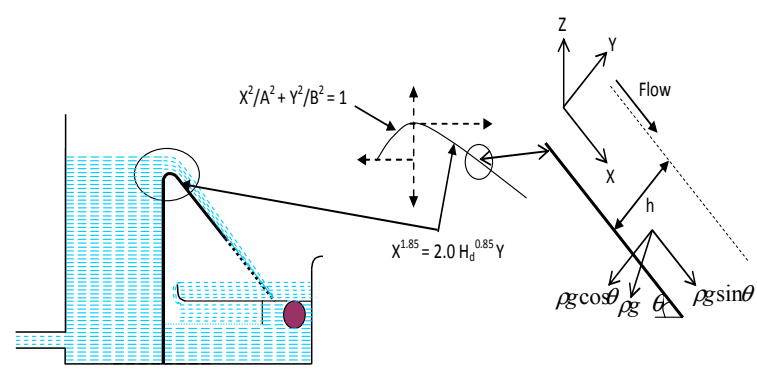

Figure 5. Breakdown flow component of the experimental device

After incorporating all assumptions and components of body forces the equations 1 and 2 reduce to:

$$
\begin{aligned}
& g \sin \theta+v d^{2} u / d y^{2}=0 \\
& -g \cos \theta-1 / \rho \partial / \partial y=0
\end{aligned}
$$

From equation (6)

$\delta \mathrm{P} / \delta \mathrm{y}=-\rho \mathrm{g} \cos \theta$ that leads to

$$
P=-\rho g y \cos \theta+C
$$

at $\mathrm{y}=\mathrm{h}, \mathrm{P}=0$ atmospheric pressure i.e. $\mathrm{C}=\rho \mathrm{gh}$. Therefore expression for pressure becomes, $P=\rho g \cos \theta(h-y)$

Now integrating equation (2.5) twice with respect to y yields,

$u_{x}=-g / v \sin \theta^{y^{2}} / 2+C_{1} y+C_{2}$

At boundary condition $\mathrm{y}=0, \mathrm{u}_{\mathrm{x}}=0$ i.e. $\mathrm{C}_{2}=0$; again at $\mathrm{y}=\mathrm{h}, \mathrm{du}_{\mathrm{v}} / \mathrm{dy}=0 ; \mathrm{C}_{1}=\mathrm{gh} \sin \theta / \mathrm{v}$;

$u_{x}=\frac{\rho g}{2 \mu} \sin \theta\left(2 h y-y^{2}\right)$

To get the shear stress at the boundary, applying Newton's law of viscosity-

$$
\begin{gathered}
\tau_{x y}=\mu d u_{x} /\left.d y\right|_{y=0}=\mu\left\{g \frac{\sin \theta}{v}(h-y)\right\}_{y=0}, \text { which gives } \\
\tau_{x y}=\rho g h \sin \theta(\text { as } \mathrm{y}=0)
\end{gathered}
$$

$\mathrm{q}$ is the flow per unit width,

$q=\int_{0}^{h} u_{x} d y=\int_{0}^{h} \frac{\rho g}{2 \mu} \sin \theta\left(2 h y-y^{2}\right) d y=\frac{1}{3 \mu} \rho g h^{3} \sin \theta$

$\&$ average velocity,

$$
v=q / h=\frac{1}{3 \mu} \rho g h^{2} \sin \theta
$$

In the above equations, substituting inflow and weir surface angle with the horizontal, unit width of the weir, different hydrodynamic parameters were calculated. US Army Corps (1952) had developed standard shapes for downstream profile of the ogee weir, defined by equation,

$\mathrm{X}^{1.85}=2.0 \mathrm{H}_{\mathrm{d}}^{0.85} \mathrm{Y}$

The depth of water upstream of the spillway $\mathrm{H}_{\mathrm{d}}$ is calculated from the non-dimensional equation for discharge given by,

$Q=\frac{2}{3} C_{0} \sqrt{2 g} L H_{e}^{3 / 2}$

Where, $\mathrm{Q}=$ total discharge; $\mathrm{L}=$ lateral crest length or width; $\mathrm{H}_{\mathrm{e}}=$ total head upstream from the crest; $\mathrm{g}=$ gravitational constant; and $\mathrm{C}_{0}=$ discharge coefficient. As the velocity head is relatively very small with total head $\mathrm{H}_{d}$ is consider equal with $\mathrm{H}_{\mathrm{e}}$ which is $7.16 \mathrm{~cm}$ (that is, $\mathrm{h} / \mathrm{H}_{\mathrm{d}}$ greater than 1.33 and $\mathrm{H}_{\mathrm{e}}=\mathrm{H}_{\mathrm{d}}$, for the approach velocity head is negligible Chow (1959). The curve of the ogee weir surface is drawn from the equation

$\mathrm{Y}=1.744 \mathrm{X}^{1.85}$

The position $(0,39.5)$ is the starting coordinate over the ogee weir and different parameters are calculated based on different points are taken on the curve. The slope angles are used to calculate the analytical results for velocity, water level and shear stresses. 


\section{RESULT DISCUSSION}

To understand flow reflections, CFD simulated water levels at left, middle and right sections along the flowpath were extracted from the modeled results. These results were compared with the one-dimensional analytical solution considering steady, incompressible fluid. Analytical formulation is unable to include flow reflections from the wall. A model result shows the dominant effect of flow reflection in the relatively small sewer overflow device as shown in Figure 6. The CFD simulated results show that due to flow reflection under condition1 (inlet parallel to the weir), water level at right side is overriding the water levels at middle and left sections. Whereas, under Condition 2 (inlet perpendicular to the weir), reflected flow contributes to elevated water levels towards both the left and right sides of the device. However towards the bottom of the inclined surface, the flow becomes uniform (across the width). The reflected water level in the right side reduces as the flow travels downstream of the ogee weir (Condition1). Condition 1 can provide better screening effect on the right side considering high water level to generate higher velocity and shear stress, however condition 1 is not favorable to achieve decent screening for left side.

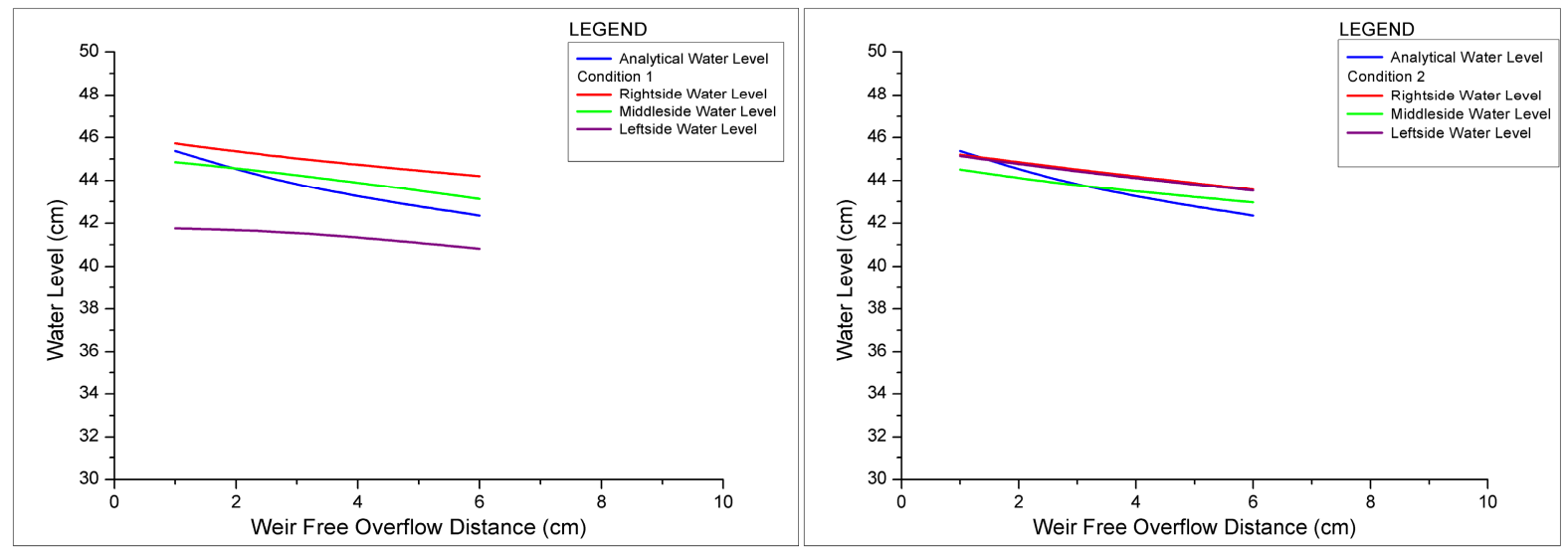

Figure 6. Comparison of water level along the flow for Position 1 and 2, showing water level from the top of the weir head

Figure 7 shows how the velocity changes over the weir. As the flow propagates downstream of the weir, the velocity at the bottom increases three times the velocity over the ogee weir in both cases, that will effectively increase the self-cleansing capacity of the device. To understand how the velocities change due to the reflection effect at different sections, comparison of velocities at different inlet orientations are shown as 'Position 1' and 'Position 2'.
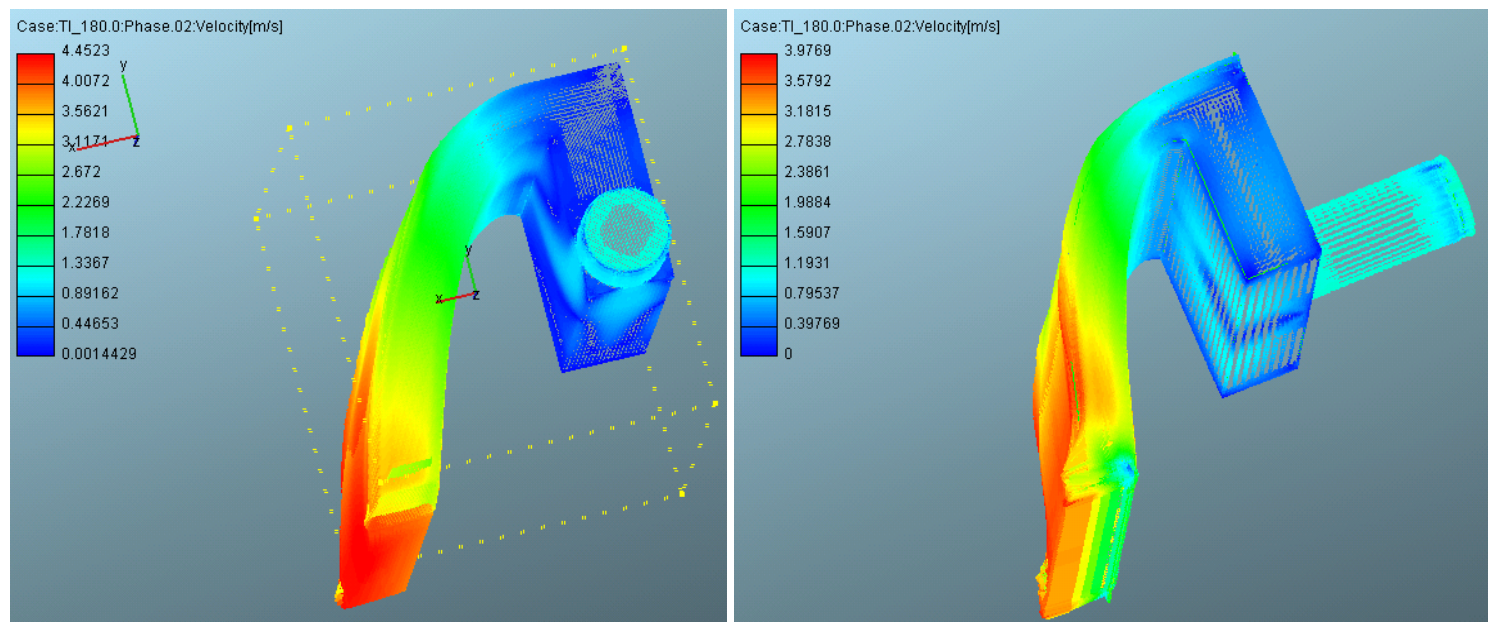

Figure 7. Velocity vector at parallel (left) and perpendicular (right) inlet to the weir directions

Due to varying water levels (high water level near the right side and low water near the left side), near the top of the weir surface, the self-cleansing property will not be as effective near the top region at Condition1. If screens are provided near the top of the weir surface as Condition1, only the right-hand side strip will get efficient self-cleansing while the left side holes are likely to be blocked by larger pollutants in the sewer water. However as flow becomes uniform (across the width) near the bottom of the weir surface, the self-cleansing capability can be achieved. Keeping this in mind, it is proposed to provide perforations (circular holes) near the bottom of the weir surface. As the water flows down, its velocity increases due to gravitational acceleration. The CFD simulated shear stress is lower than the analytical value as it is unable to consider flow undulations. Moreover analytical calculation assumed an in-viscid fluid domain without having any boundary layer effect while CFD simulation considered viscous boundary effects. 


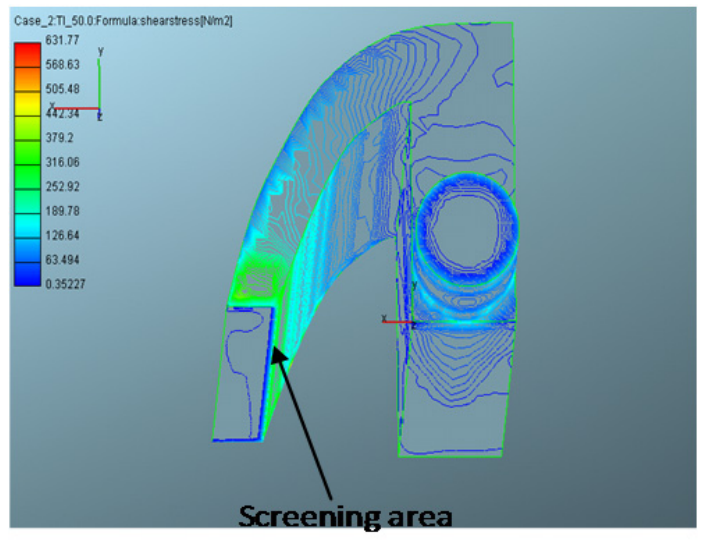

Figure 8. Shear stress distributions at parallel inlet to the weir directions

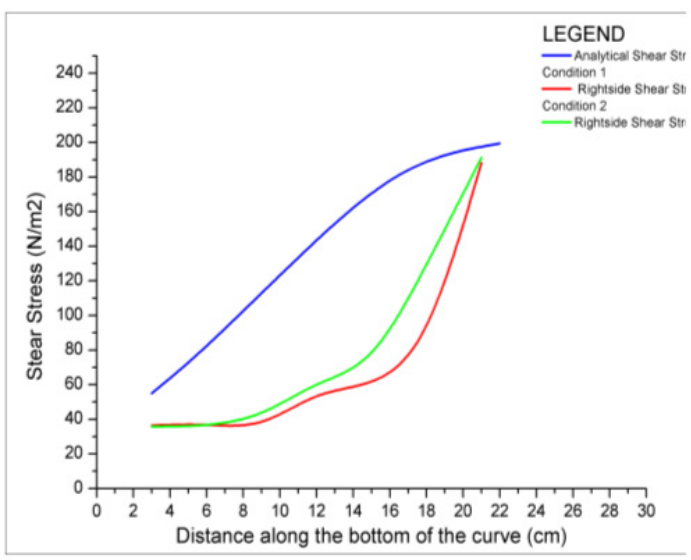

Figure 9. Comparison of shearing stress along the bottom of the curve surface

As the sewer overflow device is small, the reflection effect was found to be dominant in the CFD results. CFD results show that the flow is not uniform (across the width of the inclined surface) near the top of the inclined surface due to the flow reflections by the rectangular box wall of the device. However, the flow becomes uniform near the bottom of the inclined surface with significant amount of shear stress. This suggests that the perforations should be placed near the bottom of the inclined surface to achieve an effective self-cleansing capability for the device. Uniform flow towards the bottom of the inclined surface will help to remove any pollutants adhered to the perforations. An analytical solution for the flow over the inclined surface was derived for one-dimensional flow. CFD results were compared with the one-dimensional analytical results for different flow parameters. The onedimensional analytical solution as expected was unable to produce three-dimensional flow reflection effects. Discrepancies with numerical results have been discussed. CFD and Analytical comparison provide an excellent opportunity to design the screener device in a way to maximize its functionality, effectiveness in trapping sewer solids with high efficiency both in terms of capture sewer solids and self-cleansing mechanism.

\section{REFERENCES}

AVL (2008). AVL Fire CFD Solver v8.5 manual, A-8020 Graz, Austria, www.avl.com

Aziz, M.A., Imteaz, M.A., Choudhury, T.A. and Phillips, D. (2013). Applicability of artificial neural network in hydraulic experiments using a new sewer overflow screening device. Australian Journal of Water Resources, 17 (1), 77-86.

Aziz, M.A., Imteaz, M.A., Choudhury, T.A. and Phillips, D.I. (2011). Artificial Neural Networks for the prediction of the trapping efficiency of a new sewer overflow screening device. 19th International Congress on Modelling and Simulation, Perth, December 2011.

Chow, V.T. (1959). Open-channel hydraulics, McGraw-Hill, New York, pp. 365-380.

Faram, M.G., Andoh, R.Y.G. and Smith, B.P. (2001). Optimised CSO screening: A UK perspective. 4th Novatech International Conference on Innovative Technologies in Urban Drainage, Lyon, France, 25-27 June, 2001.

Metcalf and Eddy (1991). Wastewater Engineering, Treatment, Disposal and Reuse, Third Ed., Boston, MA: McGraw-Hill, Inc. pp. 448-451.

Moffa, P.E. (1997). Scarborough CSO project-review of CSO screen application, report prepared for the City of Scarborough, Municipality of Metro, Toronto, ON.

Simon. M. and Phillips, D.I. (2008). The development of a sewer solids screening system for CSO chambers. 11th International Conference on Urban Drainage, Edinburgh, Scotland, UK 2008.

Stelling, G.S. (1984). On the construction of computational methods for shallow water equations, Rijkswaterstaat communication No. 35.

U.S. Army Corps of Engineers (1952). Corps of Engineers Hydraulic Design Criteria and Hydraulic design of spillways, EM 1110-2-1603, Department of the Army, Washington, D.C. 